\title{
Bel ağrısı olan hastalarda lomber sagittal denge bozuklukları mutlaka akla getirilmelidir
}

\section{Lumbar sagittal imbalance should be considered in patients with low back pain}

\author{
Mehmet Bülent Balioğlu, Akif Albayrak, Yunus Atıcı
}

S.B. Metin Sabancı Baltalimanı Kemik Hastalıkları Eğitim ve Araştırma Hastanesi, Omurga Cerrahisi ve Artroplasti Kliniği, İstanbul

\begin{abstract}
Ağrı, omurga dengesizliği olan erişkinlerde en yaygın belirtilerden biridir. Bel ağrısı ile birlikte, sıklıkla sagittal denge bozuklukları da olabilir. Sagittal düzlemde görülen uyum bozuklukları, ağrı ve sakatlığın giderek artan bir nedeni olarak kabul edilmektedir. Sagittal dengenin, omurga deformiteli erişkin bir hastanın klinik durumu için en önemli ve güvenilir bir radyolojik gösterge olduğu gösterilmiştir. Radyolojik incelemeler ile birlikte, global uyum, bölgesel ve pelvik parametreler de değerlendirilmelidir. Bel ağrısı ile eşlik eden sagittal plan deformiteleri radyolojik olarak değerlendirilirken, özellikle lomber lordoz, sagittal vertikal aksis, pelvik insidans, sakral eğim ve pelvik tilt ölçülmelidir. Bel ağrısı ile birlikte erişkin omurga deformitesi olan hastalarda, Scoliosis Research Society - Schwab sınıflama sistemi kullanılarak, koronal plan deformiteleri yanı sıra sagittal plan değişiklikleri de değerlendirilmelidir. Sagittal planda uyum eksikliği, ağrı, deformite ve sağlıkla ilgili yaşam kalite skorlarında yetersizlik ile sonuçlanabilir. Sagittal düzlemde pozitif bir dengesizlik, sağlıkla ilgili yaşam kalite skorlarında azalmaya yol açarken, sagittal düzlem deformitelerinin cerrahi sonrası olarak düzeltilmesi ile, anlamlı bir iyileşme de gösterilmiştir. Bu nedenlerden dolayı, bel ağrısı olan hastalarda sagittal denge bozuklukları ve hasta yaşam kalite fonksiyonel sonuçları, değerlendirme ve tedavinin planlanması açısından göz önünde tutulmalıdır.
\end{abstract}

Anahtar sözcükler: bel ağrısı; omurga deformiteleri, erişkin; denge, sagittal; dengesizlik, sagittal
Low back pain is one of the most common symptoms in adults with spinal imbalance. Sagittal imbalance may be seen together with low back pain. Alignment disorders of the sagittal plane are widely seen as the increasing cause of pain and disabilities. It has been shown that the existence of adult spine deformity in patients with sagittal balance is the most important and reliable radiologic indicator for the health related quality of life. Global alignment, regional and pelvic parameters should be considered together with radiologic examinations. In radiological evaluation of sagittal plane deformities accompanied with low back pain, one should measure lumbar lordosis, sagittal vertical axis, pelvic incidence, sacral slope and pelvic tilt. In patients with low back pain having adult spinal deformity, changes in sagittal plane, as well as coronal plane deformity should be evaluated by using Scoliosis Research Society - Schwab classification system. Deficiency in sagittal plane alignment may result in pain, deformity, and low quality of life related to health of the patient. It has been shown that a positive imbalance in sagittal plane caused a decrease in health related quality of life, whereas the postoperative correction of sagittal plane deformities showed a significant improvement. In accordance with these results, sagittal imbalance in patients with low back pain and health related quality of life scores should be noted for the evaluation and planning of the treatment.

Key words: low back pain; spinal deformities, adult; balance, sagittal; imbalance, sagittal rişkin omurga deformiteleri (EOD), sıklıkla omurganın koronal ve/veya sagittal planda dekompansasyon nedeni olan idiyopatik skolyoz yanı sıra, de novo veya dejeneratif eğrilikleri de içeren geniş bir tanısal sınıflamadır. ${ }^{[1]}$ EOD, sağlıklı ve yaşı nüfusta \%68 kadar yüksek oranda tıbbi bir sorun olarak öne çıkmaktadır. ${ }^{[2]}$ Son yıllarda, erişkin hastalarda özellikle sagittal düzlemde görülen uyum bozuklukları, ağrı ve sakatlığın giderek artan bir nedeni olarak kabul edilmektedir. ${ }^{[3]}$ Omurga deformiteleri ile birlikte, erişkinlerde çoğunlukla pozitif sagittal denge ortaya çıkar ve bu durum, önemli aktif kompansatuvar mekanizmalar olmadan hastaların dik duruşunu sürdürmesini olanaksız hale getirir. ${ }^{[4]}$ Bu kompansatuvar

- Illetişim adresi: Dr. Mehmet Bülent Balioğlu, S.B. Metin Sabancı Baltalimanı Kemik Hastalıkları Eğitim ve Araştırma Hastanesi, Ortopedi ve Travmatoloji Kliniği, Baltalimanı, Sarıer, İstanbul Tel: 0532 - 2521483 e-posta: mbbalibey@gmail.com

- Geliş tarihi: 17 A ğustos 2015 Kabul tarihi: 17 Ağustos 2015 
mekanizmaları oluşturan pelvik retroversiyon, diz fleksiyonu veya kalça hareket kısıtlılığı, hastalar için büyük rahatsızlık ve özürlülük kaynağı olabilir. ${ }^{[4-6]}$ Son 15 yıldır yapılan çalışmalarda da belirtildiği gibi, sagittal düzlemdeki pozitif bir dengesizliğin sağlıkla ilgili yaşam kalite skoru (health related quality of life HRQOL)'nda azalma ile doğrudan ilişkisi ve sagittal düzlem deformitelerinde gözlenen cerrahi sonrası düzelmenin, hasta sonuçlarında anlamlı ölçüde iyileşme gösterdiği bulunmuştur. ${ }^{\left[{ }^{[5]}\right]}$ Pozitif sagittal dengenin, cerrahi sonuçlardan bağımsız olarak, omurga deformiteli hastalarda olumsuz sonuçlar ile güçlü bir şekilde ilişkisi olduğu gösterilmiştir. ${ }^{[4-6,10]}$ Özellikle EOD ile birlikte klinik şikayeti olan hastalar için en uygun tedavi planlanırken, HRQOL sonuçları ile ilişkili radyografik parametrelerin daha iyi anlaşılması gereklidir ve bu parametrelerin geliştirilmesi için çalışmalar devam etmektedir. ${ }^{[11]}$ EOD'nin değerlendirilmesi için; eğrilik derecesi, korreksiyon miktarı, sagittal ve koronal denge ve HRQOL enstrümanları kullanılır. Hastaların sonuçlarını değerlendirmek için, büyük çoğunlukla Oswestry Disability Index (ODI), Scoliosis Research Society (SRS) - 22, Scoliosis Research Society (SRS) - 24, Short Form - 36 (SF-36) ve görsel ağrı cetveli (visual analog scale - VAS) gibi HRQOL sorgulamaları tercih edilmektedir. ${ }^{[9]}$ Günümüzde, radyografik parametreler ve HRQOL ölçümleri arasındaki ilişki ayrıntılı olarak tanımlanmış ve Scoliosis Research Society (SRS) -Schwab sınıflaması ile bunun önemi vurgulanmıştır. ${ }^{[11,12]}$ Son yapılan çalışmalar ile, sagittal dengenin omurga deformiteli erişkin hastalarda klinik sağlık durumu için en önemli ve güvenilir radyolojik gösterge olduğu gösterilmiştir. ${ }^{[4,6,11,13-18]}$ Bel ağrısı olan hastalarda, buna neden olan sagittal denge bozukluklarının radyografik olarak ayrıntılı değerlendirilmesi yanı sıra, bunun hasta yaşam kalite fonksiyonel sonuçları ile yakın ilişkisi incelenmelidir.

\section{BEL AĞRISI VE LOMBER SAGITTAL DENGE BOZUKLUKLARININ NEDENLERI}

Ağrı ve sagittal dengesizlik gibi klinik belirtilere yol açan başlıca nedenlerden biri olan EOD, birçok şekilde ortaya çıkabilir. EOD, yaşamın erken dönemlerinde karşılaşılan rezidüel deformiteler, dejeneratif problemler veya her ikisinin kombinasyonuna bağlı olabilir. Nedeni bilinmeyen etkenler (idiyopatik skolyoz), konjenital anomaliler (segmentasyon bozukluğu) ve nöromusküler durumlardan (serebral palsi, spinal kord yaralanması veya spina bifida) kaynaklanabilir. EOD; travma, enfeksiyon, malignensi, dejeneratif hastalıklar veya iyatrojenik nedenlerin sonucu olarak da görülebilir. Ağrı belirtisi ve sagittal plan deformiteleri, yaş ile farklılık gösterebilir. Orta ve daha ileri yaşlı erişkinlerde omurga deformiteleri için en yaygın nedenler, dejeneratif (de novo) skolyoz, dejeneratif kifoz ve iyatrojenik iken, genç erişkinler arasında en yaygın neden, tedavi edilmemiş adolesan idiyopatik skolyoz (AiS)'dur. ${ }^{[19]}$ Sagittal dengesizliğe, klasik olarak ankilozan spondilit yanı sıra, iyatrojenik nedenler de yol açabilir. Özellikle, lomber bölgede omurgalara uygulandığı zaman posterior kolonda uzamaya yol açan Harrington distraksiyon enstrümantasyon sistemleri ve anterior kolonu kısaltan enstrümantasyonların (Zeilke ve Dwyer gibi) buna neden olduğu bildirilmiştir. Günümüzde ise, bu tekniklerin yaygın uygulaması bırakıldığından, daha çok postlaminektomi deformitelerinin ve sagittal dengenin yeteri kadar restore edilemediği iyatrojenik postfüzyon kifoza yol açan diğer nedenlerin, sagittal denge bozukluklarına yol açtığı görülmektedir. Özellikle uzun omurga füzyonlarının üstünde veya altındaki psödoartrozis, bozulma, yetmezlik veya kırıklar, ${ }^{[20]}$ vertebra kırıkları için kısa füzyon ile uzun rod uygulamaları sonrası uzun süre hareketsiz kalan füzyon dışı bölgede yer alan faset eklem artrozu nedeniyle, bel ağrısı görülebi$\operatorname{lir}$ (Tablo 1). ${ }^{[21]}$

Tablo 1. Bel ağrısı ve sagittal dengesizliğe yol açan nedenler

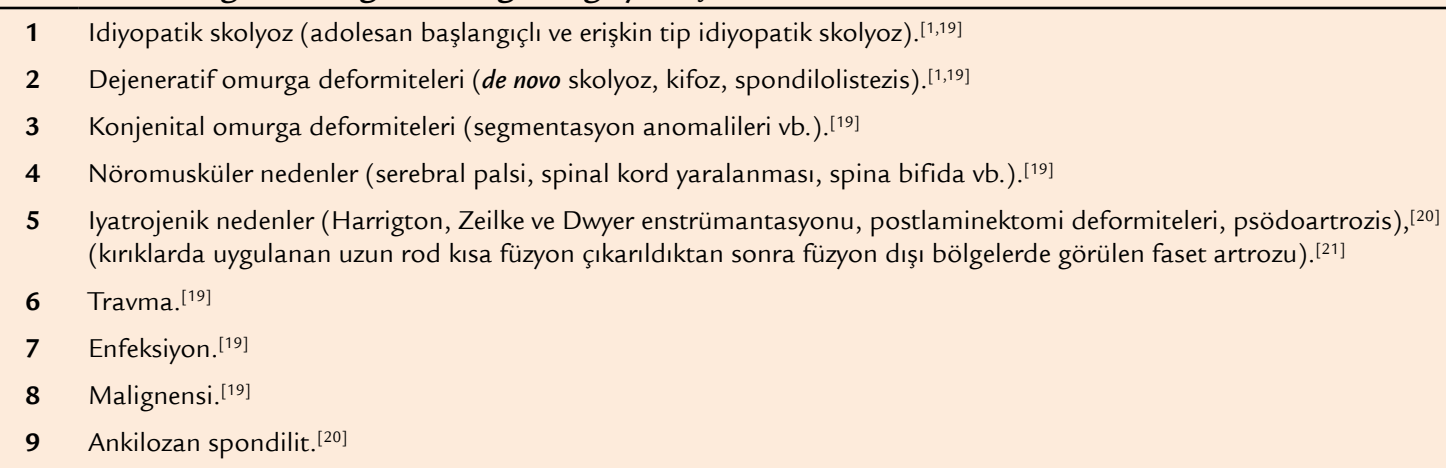




\section{KLINIK DEĞERLENDIRME}

Omurga deformitesi aksiyel, koronal ve sagittal düzlemleri etkileyerek gözlemlenebilen bütün anormallikleri bir arada içerebilir. Skolyoz, klasik koronal görüntülemede omurganın lateral bir eğriliği olarak tanımlanmış olmasına rağmen, genellikle üç boyutlu bir deformite olarak, aynı zamanda bir rotasyonel (aksiyel deformite), kifotik veya lordotik komponenti (sagittal deformite) de içerebilir. Anormal sagittal spinal profil (kifoz veya lordoz), bir primer deformite olarak veya diğer deformiteler ile birlikte olabilir. Dengesiz artmış kifoz deformitesi, pelvis ve ayakların üstünde başın normal postürü (fizyolojik sagittal uyum) öne kayarak, pozitif sagittal dengesizlik ile sonuçlanır. Spondilolistezis ise, bir vertebranın anterior veya posterior komşu seviyeden yer değiştirdiği, sagittal planda bölgesel bir anormallik olarak görülebilir. ${ }^{[19]}$ Genellikle kozmetik veya deformitenin ilerlemesi ile ilgili kaygıları olan omurga deformiteli Ais'in aksine, erişkinler için en yaygın belirti, ağrı ve günlük aktivitelerde gözlenen kısıtlılık olmaktadır. ${ }^{[22-25]} \mathrm{Bu}$ nedenle; hastalarda ağrının kalitesi, yoğunluğu, yeri ve zaman içindeki değişiminin dökümante edilmesi çok önemlidir. ${ }^{[19]} \mathrm{Hem}$ bacak ağrısında hem de aksiyel bel ağrısında, artma ve azalmaya hangi faktörlerin yol açtığı ve etkisi açıklığa kavuşturulmalıdır. ${ }^{[23-25]}$

Omurga deformiteli erişkin hastalarda, bazen nörolojik defisit ile karşılaşılabilir ve eğer varsa, ortaya çıkarmak için çok dikkatlice değerlendirilmelidir. ${ }^{[26]}$ Motor zayıflık veya değişimi, ya da duyu azalması öyküsü, barsak ve mesane disfonksiyonları araştırılmalıdır. Birlikte eşlik eden miyelopatinin belirtileri, diskordinasyon ve yürüme düzensizliği kontrol edilmelidir. Torakolomber deformite hasta fonksiyonlarını ve tedavi yaklaşımlarını etkileyebileceği için, üst ekstremitelerde kas zayıflı̆̆ı, hissizlik veya diskoordinasyon gibi semptomların, eşlik eden servikal hastalıkların yansıması olabileceği göz önünde bulundurulmalıdır. ${ }^{[19]}$

Kas iskelet sistemi, normal dizilimde patolojik değişiklikler olduğu zaman cevap olarak spinopelvik kompansasyona katılabilir. ${ }^{[27]} \mathrm{Bu}$ değişikliklerin bazıları iyatrojenik nedenler iken; diğerleri, yaşlanma, disk dejenerasyonu, hiperkifozis ve lomber lordoz (LL) kaybından olabilir. ${ }^{[28-30]}$ LL'nin kaybı, öne doğru (pozitif) sagittal dizilim bozukluğuna yol açarak, lomber omurgada anormal yüklenmelere neden olur ve bu durum, intervertebral dejeneratif değişiklikler ile sonuçlanır. ${ }^{[27]}$ Vücudumuz, cevap olarak, gövde diziliminin anterior yer değiştirmesini dengeleyen karşı mekanizmalardan yararlanır. ${ }^{[27]}$ Torakolomber omurganın esnek bölgesinde olan bölgesel dengeleme telafisine ek olarak, kompansatuvar mekanizmalarda dik bir postür ve horizontal bakış sağlamak için, kalça, alt ekstremiteler ve servikal omurga gibi patoloji sahasına uzak kas iskelet sistemi bölgelerini de kullanabilir. ${ }^{[31,32]}$

\section{Fiziksel Muayene}

Erişkin omurga deformitelerinin fizik muayenesi, deformitenin tümünün (global) değerlendirmesini içermelidir. Bu, sırasıyla, supin, oturur ve ayakta dururken, ve hastanın yürüyüşü gözlenerek yapılmalıdır. Rijid torasik ve servikal deformiteler, supin pozisyonda kolayca anlaşılabilir. Kalça fleksiyon kontraktürleri, supin pozisyonda iken Thomas testi ile değerlendirilebilir. Oturma, kalçaların etkisini ortadan kaldırır, bacak uzunluk eşitsizliği ve kalça fleksiyon kontraktürü etkisi olmadan, torasik ve lomber eğrilikleri değerlendirmek için kullanılabilir. Sagittal ve koronal deformitelerin değerlendirilmesi için en uygun duruş, ayaktayken elde edilir. Hastalar, aynı zamanda dizleri ekstansiyonda ve kitlenmiş pozisyonda iken değerlendirilmelidir. İlave olarak, skolyozlu hastalar, kifoz deformitelerini (rib hump) ortaya çıarmak için, belden $90^{\circ}$ öne doğru eğilerek muayene edilmelidir. ${ }^{[19]} \mathrm{Hem}$ ayakta dururken hem de yürüme postüründe, hasta "öne eğilmiş" derecede, düzleşmiş kalça pozisyonunda olabilir veya diz fleksiyonu (crouched posture) pozitif sagittal dizilim bozukluğunu gösterebilir. Bazı nörolojik rahatsızlıklar, miyopati ve Parkinson hastalığı gibi postüral nöromusküler bozukluklar ile ilişkili Camptocormia, sıklıkla sedece yürüme testi ile belirgin hale gelebilir. ${ }^{[19]}$

Sagittal omurganın uyumu ile yaşam kalitesi ölçümleri arasında kunvetli bir ilişki vardır. ${ }^{[4,6,13-18]}$ LL büyüklügünün ayarlanmasında pelvis morfolojisi gerekli olduğu için, bunun pelvisin omurga uyumunun sağlanmasında torakal ve servikal uyum ile birlikte kritik önemde bir komponent olduğu gösterilmiştir. [13,16,18,33-39] Kompansatuvar mekanizmalar, anlamlı pozitif sagittal spinopelvik denge dizilim bozukluğu olan hastalarda belirgin olabilir. Sagittal planda başın pelvis ile uyum içinde taşınması gayreti, bu hastalarda pelvik retroversiyon ile telafi edilebilir, bu da daha anterior pozisyonda bir asetabulumla sonuçlanır. Hafif pelvis retroversiyonuna kalça ekstansiyonu eşlik edebilirken, daha ciddi veya sabit deformitelerde, kalça ve diz fleksiyonu birlikte eşlik edebilir. Kronik pozitif sagittal dizilim bozukluğu olan hastalarda, kalça fleksiyon kontraktürü gelişebilir. Öncelikle bu problemler tespit edilerek, cerrahi öncesi fizik tedavi ile çözümlenmelidir; gerekli durumlarda, sagittal uyumu dengeli bir şekilde yeniden sağlayan cerrahi yöntemlerle de önlenebilir. [19] Omurga deformitesi olan yetişkinde genel nörolojik değerlendirme; motor gücü ve duyu, kas tonusu, refleksler (periferik, karın ve patolojik refleksler), koordinasyon ve yürümenin değerlendirilmesini içermelidir. Hiperrefleksi, klonus ve bozulmuş yürüme gibi 
miyelopati belirtileri, ciddi dorsal veya birlikte servikal omurga hastalığı olan hastalarda mevcut olabilir. Bu durumun, lomber deformitelerin düzeltilmesi öncesinde servikal manyetik rezonans (MR) görüntüleme ile değerlendirilmesi gerekebilir. ${ }^{[19]}$

\section{Ăgrı}

Ağrı, omurga dengesizliği olan erişkinlerde en yaygın belirtilerden biridir. ${ }^{[20]}$ Bu durum, deformite seviyesinde anormal omurga biyomekaniğine neden olarak, çevre yumuşak dokular ve yapılar üzerinde değişikliklere yol açabilir. ${ }^{[40]}$ Ağrı, genellikle sürekli (sabit) ve acı niteliğinde, deformitenin seviyesinde veya daha üstünde olur. Omurgasında $30^{\circ}$ veya daha büyük bir açısal kifoz deformitesi olan hastalar, kronik bel ağrısı açısından gittikçe artan bir risk altındadır. ${ }^{[41]}$ Ayrıca buna, spinal stenoza yol açan ve genellikle deforme segmentin üstünde veya altındaki dejeneratif değişikliklere bağlı olarak radiküler ağrılar da eklenebilir. ${ }^{[20]}$

\section{Dengesizlik}

İdeal omurga uyumu, minimal kas enerjisi harcayarak bağımsız olarak ayakta durmaya izin verir. ${ }^{[8]}$ Normalde bu, omurganın fizyolojik ilişkileri, pelvisin morfolojisi ve aksiyel ve appendiküler iskelet kasları arasındaki kompleks ilişkiler sayesinde gerçekleştirilir. ${ }^{[1]}$ Vücudun sagittal planda pozitif dengesizliğinde artış, kas çalışma gayretinde ve enerji harcamasında artış sonucunda ağrı, yorgunluk ve sakatlığa neden olur. ${ }^{[8]}$ Global sagittal dengesizliği olan hastaların başlıca şikayeti, sıklıkla öne doğru duruştur. Nadiren tek başına görülen denge bozukluğu, sıklıkla ağrı ve yürüme toleransında azalma ile ilişkilidir. Çoğunlukla yakın çevresi tarafından fark edilir ve genellikle kötü duruş ile ilişkili olduğu sanılır. Sagittal dengesizliğin önemli ölçüde kozmetik olarak etkisi olabilir ve çoğu hasta daha yaşlı göründüğüne inanır. ${ }^{[20]}$ Sagittal dengesizlik, daha fazla sakatlık ile ilişkili bulunmuştur. ${ }^{[6,42]}$ Sagittal dizilim bozuklukları, normal lordoz veya kifozda aşırı artışa ya da yetersizliğe neden olabilir. Klinik uygulamada; olguların çoğu, inflamatuvar, dejeneratif veya post travmatik bozukluklara sekonder kifoz deformitesi nedeniyle görülür; enfeksiyon veya tümörlere sekonder de olabilir. Genellikle, yatay bakışını sürmekte yetersizliğe bağlı kendi imajı ve sosyal etkileşim kaygıları ile birlikte fonksiyonel yetersizlik ve ağrı ile ortaya çıkar. Sonuçta pelvis ve alt ekstremite postürü, normal dengenin restorasyonunun sağlanması için gayret eder. ${ }^{[43]}$

\section{Nörolojik Defisit}

Nörolojik defisit nadir bir durumdur, fakat füzyonun torasik omurgaya uzandığı hastalarda görülebilir; kavşak seviyelerde kırığa sekonder akut bir olay ile olabilir.
$\mathrm{Bu}$, genellikle uzun füzyonu takip eden erken (ilk 2-3 ay içinde) dönemde, özellikle osteoporotik hastalarda olabilir. Aynı zamanda, spinal kanalda ilerleyici stenoza yol açan füzyon üzerindeki dejenerasyona sekonder görülebilir. Torakal omurgada daha yaygın şekilde, muhtemelen rölatif dar kanal çapına sekonder görülebilir ve semptomları genellikle hafif miyelopati ile olabilir. ${ }^{[20]}$

\section{RADYOLOJiK DEĞERLENDIRME}

EOD; ağrı, instabilite, fonksiyonel özürlülük, kozmetik kaygılar, nörolojik risk ve/veya fizyolojik disfonksiyona yol açabilen fizyolojik omurga uyum anomalisi ile birlikte olan omurga sorunlarının tümünü kapsar. EOD için temel tanımlayıcı terminoloji bilgi çalışmaları, hastaların omurga tedavileri ile uğraşanlar için önemlidir. ${ }^{[19]}$ Omurga sınıflaması için, SRS terminoloji komitesi ve çalışma grubu, gelişmeye açık, doğru ve geçerli bir omurga parametreleri terminolojisi oluşturmuştur. ${ }^{[44,45]}$ Daha sonraki çalışmalar sayesinde, yeni parametrelerinde eklenmesi ile kapsamı genişletilmiştir (Tablo 2). ${ }^{[46]}$

Radyolojik tetkikler alınırken, hastaların, ayakta dik ve rahat pozisyonda, dizler mümkün olduğu kadar ekstansiyonda iken T1-S1 görülecek şekilde standart radyografileri çekilmelidir. Optimal sagittal değerlendirme için, torakolomber omurganın daha iyi görünümünü elde etmek ve kompansatuvar mekanizmalara karşı koymak amacı ile, eller ve parmak uçları anterior klavikula üzerinde olacak şekilde radyografik değerlendirme yapılmalıdır. ${ }^{[12]} \mathrm{Hem}$ sagittal deformitelerin değerlendirilmesi hem de cerrahi planlama, radyografik analiz temeline dayanmaktadır; bu bağlamda EOD ilişkili çeşitli parametreler tanımlanmıştır. $[3,7,11,12,20,47]$ Radyolojik incelemeler, başlıca üç ana başlık altında; bölgesel parametreler, global uyum ve pelvik parametreler olarak birlikte değerlendirilmelidir. Bölgesel parametreler için, torakal kifoz (TK), torakolomber kavşak, LL; global uyum için, sagittal vertikal aksis (SVA), T1-sagittal tilt (T1-SPI), T1 pelvik açı (TPA) ve proksimal torasik eğim (proksimal torasik slop - PTS); pelvik parametreler için ise pelvik insidans (PI), sakral eğim (sacral slope - SS), pelvik tilt (PT) ölçülebilir. Ayrıca, EOD hastaları, SRS-Schwab sınıflama sistemi kullanılarak, koronal plan yanı sıra sagittal planda da ayrıntılı olarak değerlendirilmelidir.

\section{Bölgesel Parametreler}

Bölgesel parametreler; TK, torakolomber kavşak ve LL'den oluşur. Sagittal planda normal şartlarda torakal ve lomber omurga açılarının, sırasıyla yaklaşık 
Tablo 2. Sagittal plan omurga parametreleri

\begin{tabular}{|c|c|c|}
\hline Parametreler & Kısaltmalar & Açıklamalar \\
\hline Torakal kifoz & TK & $\begin{array}{l}\text { Hasta sağa bakacak şekilde yan görünümde omurganın posterior dışbükey açılanmasıdır. } \\
\text { Hiperkifozis ve hipokifozis terimleri sırası ile kifozun normal aralığından daha fazla veya daha az } \\
\text { olduğu durumları ifade eder. Açı ölçümü en iyi görülen en üst torasik vertebranın üst end plate'i ve } \\
\text { torasik } 12 \text {. vertebranın alt end plate’i veya en alt kifotik vertebra arasında Cobb metodu ile ölçülür. } \\
{[43,44]}\end{array}$ \\
\hline Lomber lordoz & LL & $\begin{array}{l}\text { Sağa bakan hastada lateral görünümde omurganın anterior dışbükey açılanmasıdır. Hiperlordozis } \\
\text { ve hipolordozis terimleri lordozisin normal genişlikten sırası ile daha fazla veya daha az olduğu } \\
\text { durumları ifade eder. Ölçümü Cobb metodu ile torakal 12. vertebranın alt end platinden sakrum } \\
\text { (S1) üst end pleyti arasındaki açının ölçümü ile yapılır. }{ }^{[43,44]}\end{array}$ \\
\hline $\begin{array}{l}\text { C7 şakül çizgisi } \\
\text { (plumb line) }\end{array}$ & C7-PL & $\begin{array}{l}\text { Dikey çizgi C7 vertebera cisminin merkezinden başlayarak düz olarak yer düzlemine doğru çizilir. } \\
\text { Eğer sagittal planda çizilir ise, bu mesafe ile S1 in posterosuperior köşesi arasındaki yatay uzaklık } \\
\text { sagittal hizalama-uyumun (sagittal vertikal aksisin) ölçümünü yansıtır, C7 şakül çizgisinin sakrumun } \\
\text { anteriorunda olması pozitif değer, sakrumun arkasında olması negatif değerdir. }{ }^{43-45]}\end{array}$ \\
\hline Sagittal vertikal aksis & SVA & $\begin{array}{l}\text { 7. servikal vertebra merkezinden dikey çizgi. Bu çizgi ile posterior end plate arasındaki mesafe sagittal } \\
\text { dengeyi belirler. }{ }^{[43,44]}\end{array}$ \\
\hline Pelvik tilt & PT & $\begin{array}{l}\text { Bicoxo-fomoral eksen ile sakral end plate orta noktasını birleştiren çizgi ve dikey (vertikal) arasındaki } \\
\text { açı. }{ }^{43]}\end{array}$ \\
\hline $\begin{array}{l}\text { Sakral eğim } \\
\text { (sacral slope) }\end{array}$ & SS & Yatay (horizontal) ile Sakral end plate arasındaki açı. ${ }^{[43]}$ \\
\hline Pelvik insidans & $\mathrm{Pi}$ & $\begin{array}{l}\text { Sakral end plate'in orta noktasına dik çizgi ile femur başı merkezinden (bicoxo-femoral eksenin orta } \\
\text { noktası) sakral end plate ortasındaki aynı noktayı birleştiren çizgi arasındaki açı. }{ }^{[43]}\end{array}$ \\
\hline Proksimal torasik tilt & PTT & $\begin{array}{l}\text { En görülen proksimal torasik vertebranın üst end plate'inin orta noktasını bicoxo-femoral eksenin orta } \\
\text { noktasına birleştiren çizgi ile dikey (vertikal) arasındaki açı. }{ }^{[46]}\end{array}$ \\
\hline Torasik apikal tilt & TAT & $\begin{array}{l}\text { Torasik apikal vertebra merkezini bicoxo-femoral eksenin ortası ile birleştiren çizgi ile dikey (vertikal) } \\
\text { arasındaki açı. }{ }^{[46]}\end{array}$ \\
\hline $\begin{array}{l}\text { Proksimal torasik eğim } \\
\text { (slope) }\end{array}$ & PTS & En görünen ve en proksimal torasik vertebra üst end plate’i ile horizontal (yatay) arasındaki açı. ${ }^{[46]}$ \\
\hline Kokso-spinal açı & CSA & $\begin{array}{l}\text { Bicoxo-femoral ekseni en proksimal görünen torasik vertebraya bağlayan çizgi ile bicoxo-femoral } \\
\text { eksenden torasik apekse çizilen çizgi arasındaki açı. }{ }^{[46]}\end{array}$ \\
\hline T1 pelvik açı & TPA & $\begin{array}{l}\text { Femur başı aksisinden T1 in merkezine uzanan çizgi ile femur başı aksisinden S1 end plate ortasına } \\
\text { çizilen çizginin arasındaki açıdır. }{ }^{12]}\end{array}$ \\
\hline
\end{tabular}

20-50 $0^{\circ}$ kifoz ve ortalama $40-60^{\circ}$ (çeşitli çalışmalara göre değişen aralıkta, $31-79^{\circ}$ ) lordoz olması beklenir (Şekil 1). ${ }^{[3,43]}$ Kim ve arkadaşları ${ }^{[48]}$ TK ve LL arasındaki ilişki için, LL'nin TK'dan yaklaşık $20^{\circ}$ daha fazla olması gerektiğine dikkat çekmişlerdir. ${ }^{[48]}$ Sonuç olarak, torakal, torakolomber ve lomber uyumun bütünü ve her bir segmentin bağımsız olarak katkısı, global sagittal ve koronal denge için çok önemlidir. ${ }^{[20]}$

\section{Global Uyum}

Bölgesel yapılar ve pelvis, sagittal dengenin oluşumuna katkıda bulunan sagittal vertikal açı (SVA)'nın tüm bileşenlerinin parçalarını oluşturur. ${ }^{[11]}$ Normal sagittal denge ile kast edilen, başın pelvis üzerinde ortalanmasıdır ve bu da, C7 vertebra cisminin merkezinden düşen şakül doğrultusunun (plumb line) birinci sakral vertebranın posterior superior köşesi üzerine denk gelmesiyle olur (Şekil 2a). ${ }^{[20]}$ C7 şakül doğrultusunun yanı sıra SVA normal değerlerinin anlaşılması, sagittal dengesizliği olan hastaların değerlendirilmesinde yararlıdır. ${ }^{[11]}$ C7 şakül doğrultusu S1'in posterior-superior köşesinin anteriorunda ise, kişi öne eğimlidir; bu durum, pozitif sagittal dengeyi ifade eder (Şekil 2b). C7 şakül doğrultusu birinci sakral vertebranın posteriorsuperior köşesinin posterioruna düştüğü zaman ise, hastada negatif sagittal denge olduğu söylenir (Şekil 2c). ${ }^{[20]}$ Erişkinlerde eğrilik progresyonu değişken olabilir; idiyopatik skolyozlu hastalarda koronal planda $1 \%$ yıl oranında ilerleme olabilirken ${ }^{[49]}$, de novo dejeneratif skolyozu olan hastalarda 3,3\% yıl kadar yüksek hızla ilerleyen eğrilikler görülebilir; ${ }^{[50]}$ SVA ise yaş ile artabilir. ${ }^{[11]}$ SVA ortalama değeri, dejeneratif hastalarda idiyopatik hastalara göre daha yüksek bulunmuştur. [46] Kompansatuvar mekanizmalar olmadan torakolomber ve/veya lomber ve kifoz uyumunda artış, daha fazla pozitif sagittal dengeye yol açar. Ancak, kifotik 


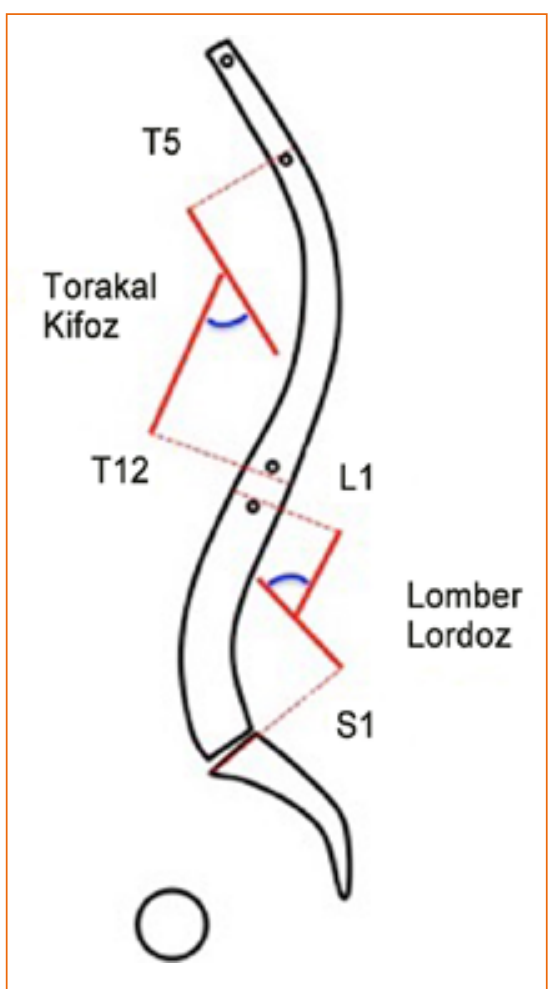

Şekil 1. Bölgesel parametreler; $\operatorname{TK}\left(20-40^{\circ}\right)$, torakolomber kavşak ve LL $\left(40-60^{\circ}\right) \cdot{ }^{[3,43,44]}$

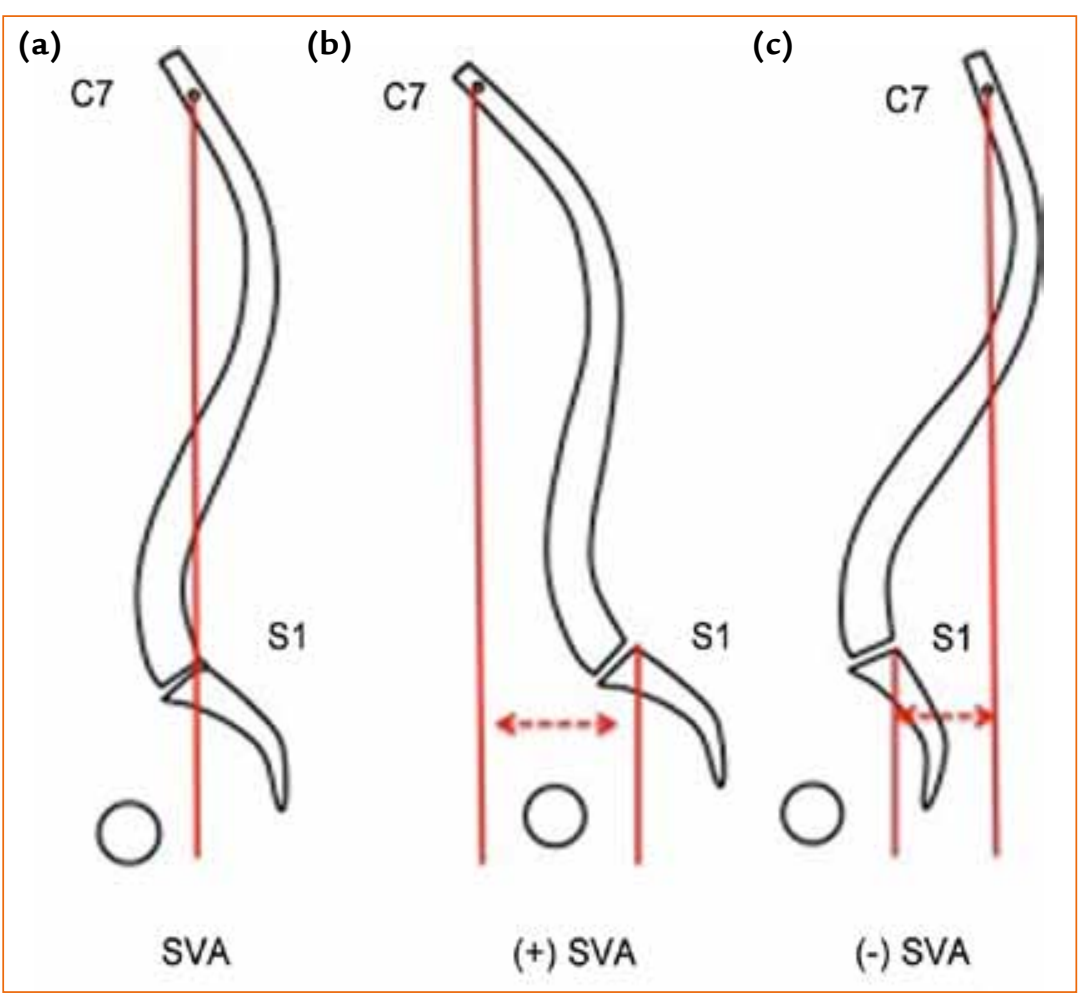

Şekil 2. a-c. Normal sagittal denge; $C 7$ vertebra cisminin merkezinden düşen şakül doğrultusu 1. sakral vertebranın posterior superior köşesi üzerine denk gelir (a). ${ }^{[20]}$ C7 şakül doğrultusu S1'in posterior-superior köşesinin anteriorunda ise pozitif sagittal denge olur (b). C7 şakül doğrultusu 1. sakral vertebranın posterior-superior köşesinin posterioruna düştüğü zaman ise hastada negatif sagittal denge gerçekleşir (c). ${ }^{[20]}$

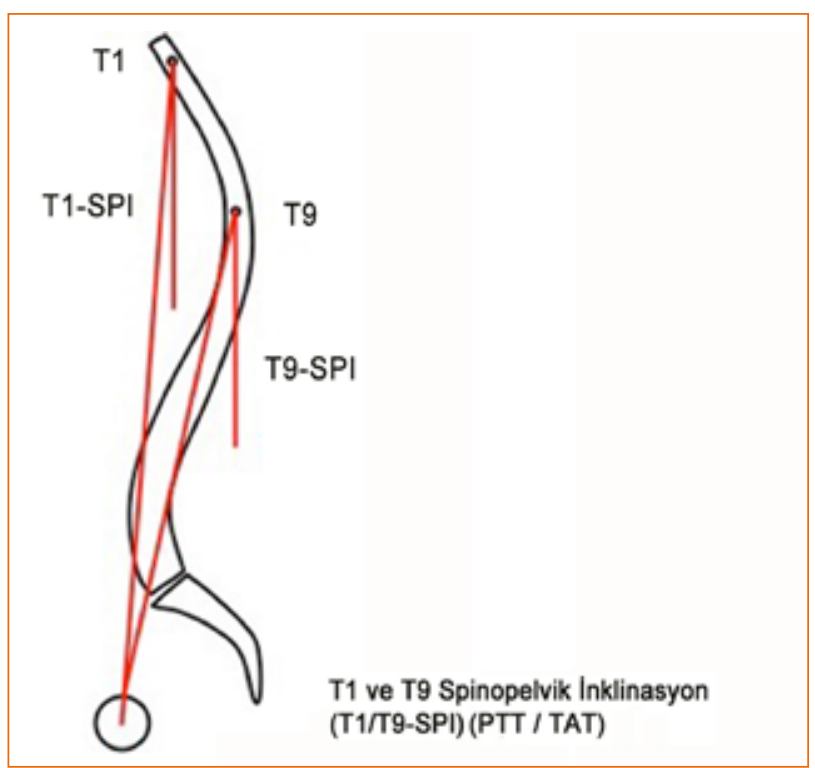

Şekil 3. T1 ve T9 tilti (T1/T9-spinopelvik inklinasyon) SVA'ya göre yetersizlik ile daha kuvvetli bir ilişki gösterir, ${ }^{[7,47]}$ ancak T9 genellikle torasik bölgesel eğriliğin apeksinin altında olmasından dolayı TK'nın tümünü kapsayabilmesi için bicoxofemoral aksise en posterior nokta olarak torasik apikal tilt (TAT) tercih edilebilir. ${ }^{[46]}$ lomber omurga deformiteli hastaların çoğu, deformitenin üstünde ve/veya altındaki dizilimdeki dengeleyici değişiklerden dolayı, normal bir global sagittal dengeye sahip olabilir. ${ }^{[20]}$

T1 ve T9 tilti, SVA göre ${ }^{[7,47]}$ yetersizlik ile daha kuvvetli bir ilişki gösterir; ancak, T9'un genellikle torasik bölgesel eğriliğin apeksinin altında olmasından dolayı, TK'nin tümünü kapsayabilmesi için, bicoxo-femoral aksise en posterior nokta olarak torasik apikal tilt (TAT) tercih edilebilir (Şekil 3). ${ }^{[46]}$ Proksimal torasik tilt (PTT) ve TAT tarafindan oluşturulan açı, coxo-spinal açı (CSA) olarak ifade edilir. ${ }^{[46]}$ CSA artan TK ile değişir ve PT ile ilişkilidir. ${ }^{[46]}$

T1 pelvik açı (TPA), hem gövde eğimini hemde pelvik retroversiyonu gösteren yeni bir açıdır. TPA, femur başı aksisinden T1'in merkezine uzanan çizgi ile femur başı aksisinden S1 endplate ortasına çizilen çizginin arasındaki açıdır (Şekil 4). Cerrahi sırasında hasta pron pozisyonda iken TPA'nın ölçülebilmesi, özellikle cerrahi uygulanacak hastaların değerlendirilmesinde ek bir avantaj sağlayabilir. TPA'nın artışı, HRQOL sonuçlarının kötüleşmesi ile ilişkilidir. Ciddi omurga deformitelerinde, TPA için sınır değer $20^{\circ}$ olarak bulunmuştur 


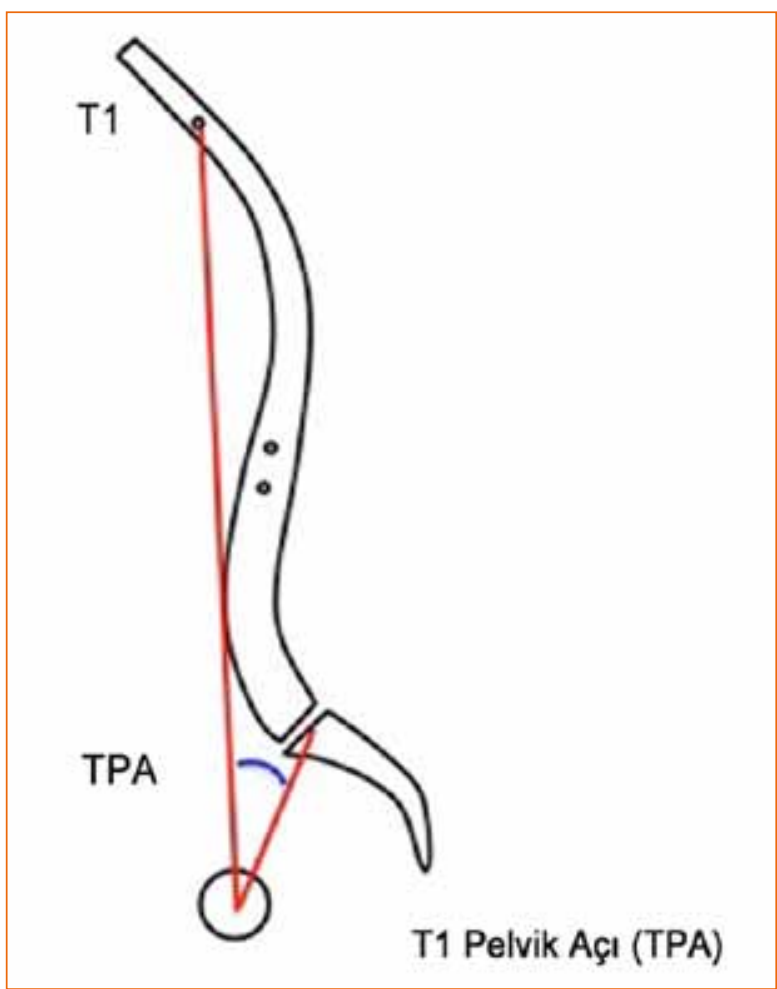

Şekil 4. T1 pelvik açı (TPA), femur başı aksisinden T1'in merkezine uzanan çizgi ile femur başı aksisinden S1 end plate ortasına çizilen çizginin arasındaki açıdır. TPA hem gövde eğimini hem de pelvik retroversiyonu gösterir.

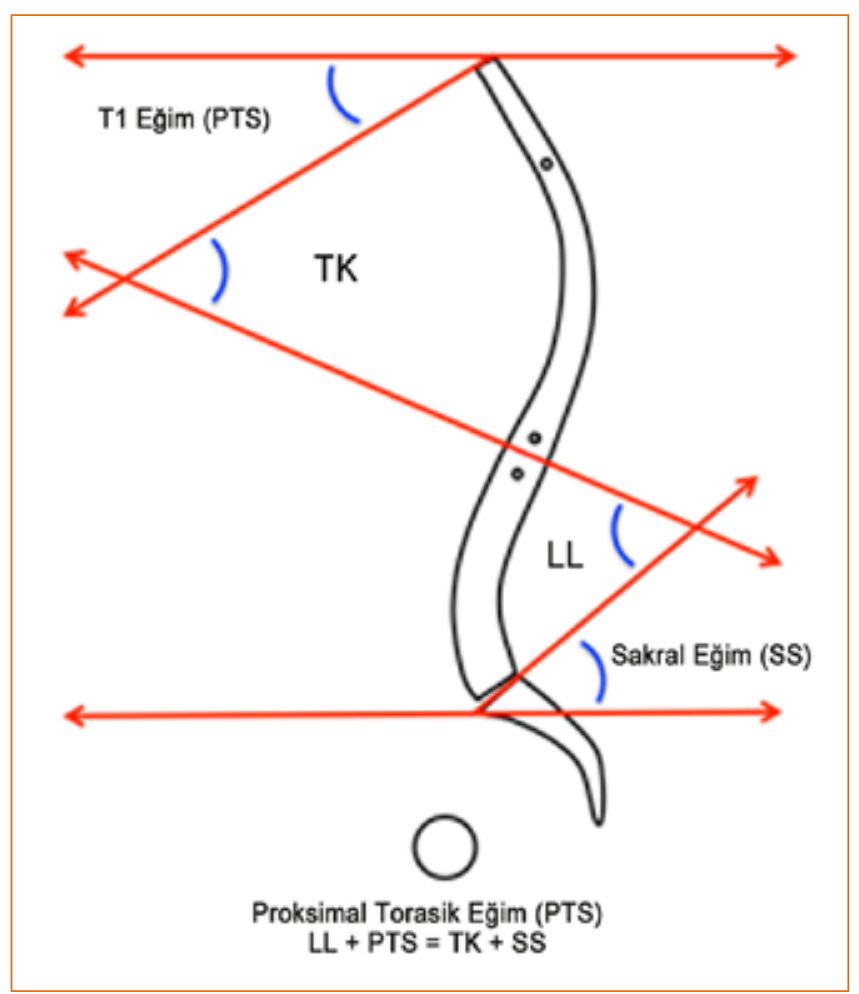

Şekil 5. LL ile diğer bölgesel açıların geometrik ilişkisi. LL + PTS $=\mathrm{TK}+\mathrm{SS}\left( \pm 2-3^{\circ}\right) \cdot{ }^{[46]}$

$6 \mathrm{a}-\mathrm{c}) .{ }^{[51]} \mathrm{PI}$ referans değeri, $51^{\circ} \pm 10^{\circ}$ veya $\mathrm{LL} \pm 9^{\circ}$ olarak gösterilmiştir ve her bir birey için sabit bir de-

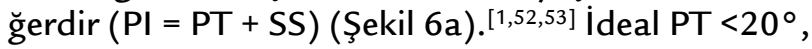
referans değeri ise $14^{\circ} \pm 5^{\circ}$ 'dir (Şekil 6b)..$^{[53]}$ Sakral eğim ise, $\mathrm{SS}=\mathrm{PI}-20^{\circ}$ veya $\mathrm{SS}=30^{\circ} \pm 9^{\circ}$ formülü ile hesaplanabilir (Şekil 6c). ${ }^{[53]} \mathrm{LL}, \mathrm{P}^{\left[{ }^{[51]}\right.}$ ve $\mathrm{SS}^{[54]}$ yanı sıra TK'dan da etkilenir ve zamanla, bu faktörlere bağlı olarak ve çeşitli nedenlerle değişebilir. ${ }^{[10,54,55]}$ $\mathrm{LL}$ değeri $=\mathrm{PI} \pm 9^{\circ}$ 'dir. ${ }^{[53]} \mathrm{PI}$, daha çok $\mathrm{LL}$ ile etkileşen ve onunla uyumlu sabit bir morfolojik parametre iken, PT ve SS, pelvik versiyonu ölçen dinamik parametreler ve sagittal denge bozukluklarında dik duruşu sürdürmeye yardımcı olan kompansatuvar mekanizmalardır. ${ }^{[1]}$ Pelvik parametreler için normal değerler kişinin yaşına bağımlıdır ve yetişkinlerde yaş ile değişiklik gösterebilir.

\section{SRS-Schwab Sınıflaması}

SRS-Schwab EOD sınıflaması, biri eğrilik tipi tanımlayıcı ve üçü ise sagittal spinopelvik (SVA, PT ve PI-LL farkı) dört değişken içeren, kabul edilmiş bir sınıflama sistemidir (Şekil 7). ${ }^{[56]}$ Schwab ve arkadaşlarının yakın zamanda (International Spine Study Group 


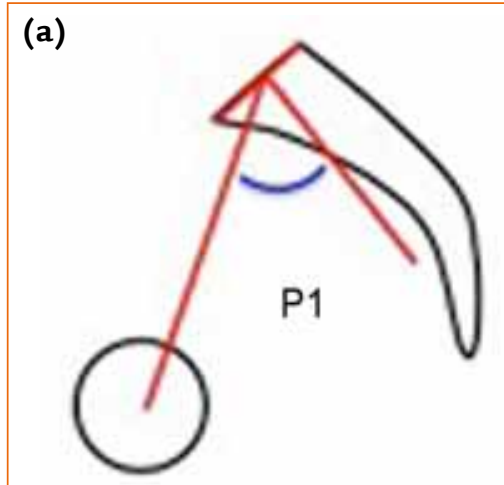

Pelvik Insidans

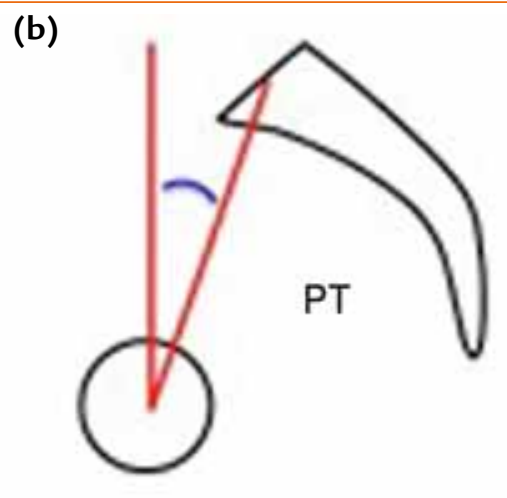

Pelvik Tilt

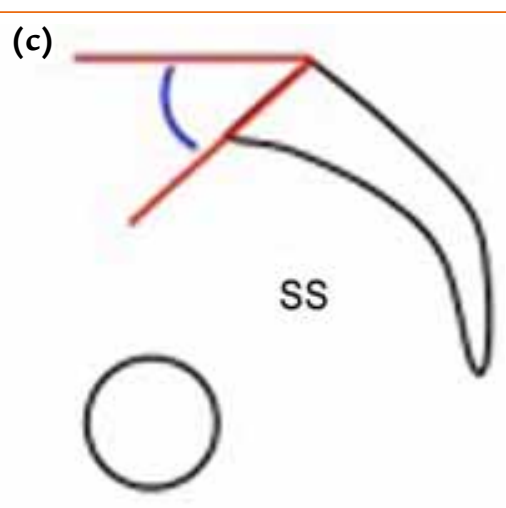

Sakral Eğim

Şekil 6. a-c. Pelvik parametreler; pelvik insidans (PI), pelvik tilt (PT) ve sakral eğim (SS), omurga ile ilgili pelvisin oryantasyonu ve şeklini ayrıntılı bir şekilde tanımlar $(\mathrm{PI}=\mathrm{PT}+\mathrm{SS}) \cdot{ }^{[51]} \mathrm{PI}$ değeri $51^{\circ} \pm 10^{\circ}$ veya $\mathrm{LL} \pm 9^{\circ}(\mathrm{a})$. $\mathrm{PT}<20^{\circ}$, referans değeri $14^{\circ} \pm 5^{\circ}(\mathrm{b})$. $\mathrm{SS}=\mathrm{PI}-20^{\circ}$ veya $\mathrm{SS}=30^{\circ} \pm 9^{\circ}(\mathrm{c})$.

\section{Sagittal Tanımlayıcılar}
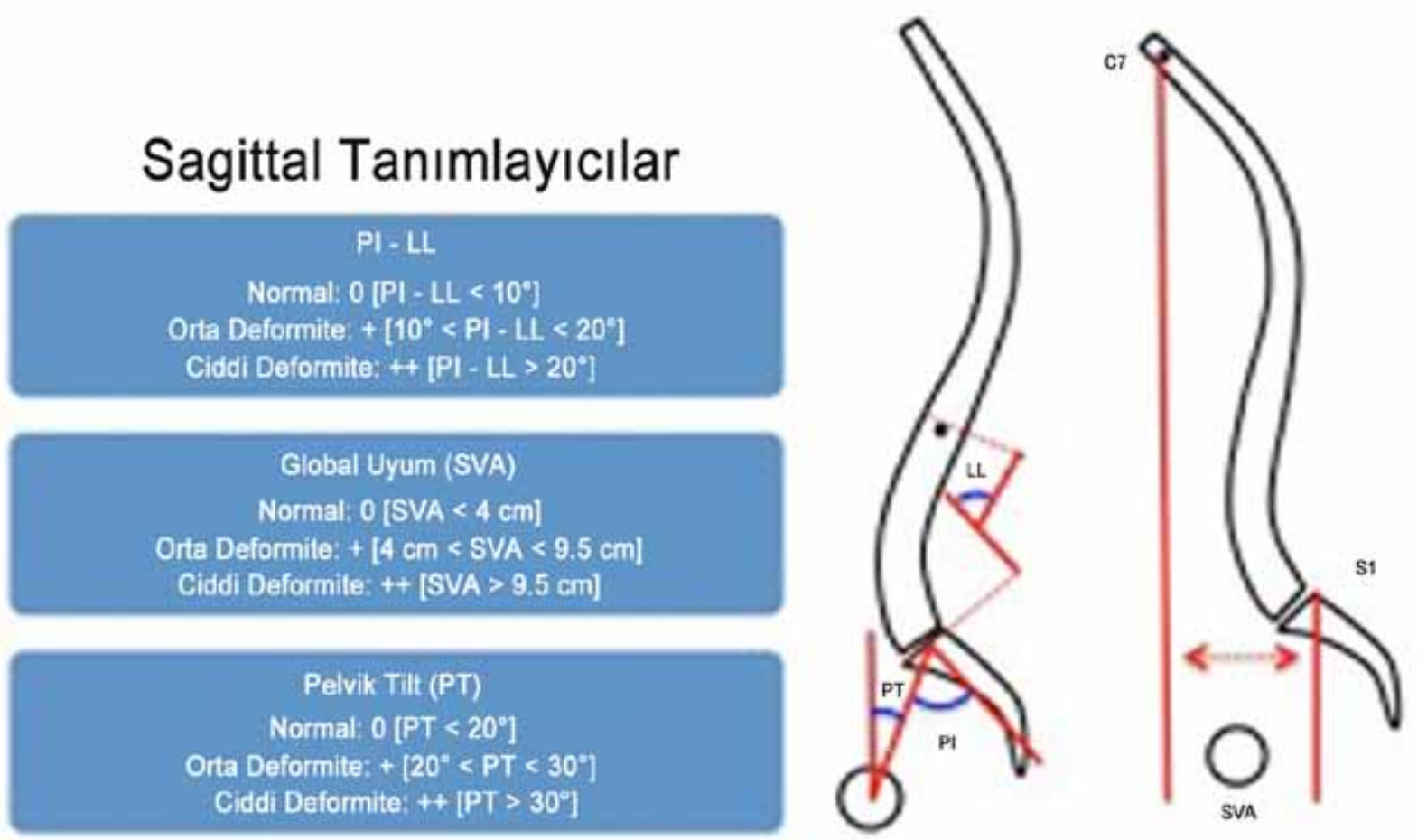

Şekil 7. SRS-Schwab EOD Sınıflama Sistemi: (PI-LL, SVA, PT) Biri eğrilik tipi tanımlayıcı ve üçü ise sagittal spinopelvik değişken içeren (SVA, PT ve PI-LL farkı) kabul edilmiş bir sınıflama sistemidir. ${ }^{[56]}$ Şekilde sadece sagittal parametreler kullanılmıştır.

ile) çok merkezli yaptıkları ileriye dönük çalışmada, radyografik parametreler ve sakatlık ölçümleri arasındaki en büyük korelasyon, kötü yaşam kalitesi ile güçlü doğrudan ilişkili olan LL ve PI arasındaki fark ile sagittal ölçümler olduğu gösterilmiştir. ${ }^{[39]}$ Sagittal denge için $\mathrm{SVA}<5 \mathrm{~cm}, \mathrm{PT}<25^{\circ}$ ve $\mathrm{LL} \approx \mathrm{PI} \pm 9^{\circ}$ olması beklenir.

\section{ÇIKARIMLAR}

Sagittal düzlem dizilim bozukluklarıyla, ağrı ve sakatlığın giderek artan nedeni olarak karşılaşılmaktadır. ${ }^{[3]}$ Omurga bozukluklarının tedavisinde, sagittal düzlem uyumunun etkisi kritik önem taşır. Bu düzlemdeki dizilim bozukluğunun yetersizliği, sadece ağrı ve deformite açısından değil, aynı zamanda sosyal etkileşim 
ve yaşam kalitesinde bozulmaya yol açmaktadır. ${ }^{[43]}$ Sagittal denge ilkelerinin iyi anlaşılması, spinal bozuklukların tedavisinde en iyi sonuçlara ulaşmak için hayati önem taşır. Patolojik süreçler ve yaşlanma ile bu denge bozulabilir. Bu da, pelvis ve alt ekstremitelerde uyumsal farklılıklara ${ }^{[43]}$ ve pelvik postürde omurga uyumunu etkileyen değişikliklere yol açabilir. ${ }^{[57]}$ LL kaybı ve lomber kifoz gelişimi, hastaların sakatlığında artışa yol açmaktadır. Sagittal omurga dengesizliğine, iyatrojenik nedenlerden genetik ve metabolik nedenlere kadar pek çok faktörün neden olabileceği unutulmamalıdır. ${ }^{[43]}$ Bel ağrısı olan yetişkin hastaların değerlendirilmesi ve omurga deformitelerinin düzeltme cerrahisinin planlanabilmesi için, sagittal planın doğru bir profil ve postür analizi gereklidir. Bir hastanın sagittal planda dik duruşunu analiz etmek için, omurganın uyumlu bir şekilde hizalanmasını oluşturan, segmental, bölgesel ve global parametrelerin ilişkisinin bilinmesi çok önemlidir. ${ }^{[46]}$ Omurga dengesi bozuk, bel ve bacak ağrı semptomları olan hastalarda, cerrahi tedavinin konservatif tedaviye göre üstün olduğu bilinmektedir. ${ }^{[24]}$ Omurga deformiteli hastalarda nötral sagittal denge için; C7 şakül doğrultusu ile posterior sakral end plate mesafesi $5 \mathrm{~cm}$ içinde tanımlanmalı, pelvis herhangi bir pelvik retroversiyon veya diz fleksiyonu ile kompanse edilmemeli ve fleksiyon kontraktürü veya kalça hareketlerinde kısıtlılık olmamalıdır. ${ }^{[46]}$ Bu parametreler ile, bel ağrısı ile sagittal plan deformitelerin ilişkisinin daha iyi anlaşılması yanı sıra, cerrahi sonrası sagittal dengenin daha doğru bir şekilde tahmin edilmesi sağlanabilir. Bu sayede, bel ağrısı olan hastalarda sagittal denge problemlerinin daha iyi anlaşılmasının sağlanmasıyla birlikte, tedavinin planlanması ve rezidüel pelvik tilt ve/ veya proksimal kavşak yetmezliği gibi geç komplikasyonlara neden olan risklerin önlenmesi mümkün olabilir. ${ }^{[8,52]}$

\section{KAYNAKLAR}

1. Savage JW, Patel AA. Fixed sagittal plane imbalance. Global Spine J 2014;4(4):287-96. CrossRef

2. Schwab F, Dubey A, Gamez L, El Fegoun AB, Hwang K, Pagala M, Farcy JP. Adult scoliosis: prevalence, SF-36, and nutritional parameters in an elderly volunteer population. Spine (Phila Pa 1976) 2005;30(9):1082-5.

3. Joseph SA Jr, Moreno AP, Brandoff J, Casden AC, Kuflik P, Neuwirth MG. Sagittal plane deformity in the adult patient. J Am Acad Orthop Surg 2009;17(6):378-88.

4. Glassman SD, Berven S, Bridwell K, Horton W, Dimar JR. Correlation of radiographic parameters and clinical symptoms in adult scoliosis. Spine (Phila Pa 1976) 2005;30(6):682-8.

5. Schwab FJ, Smith VA, Biserni M, Gamez L, Farcy JP, Pagala M. Adult scoliosis: a quantitative radiographic and clinical analysis. Spine (Phila Pa 1976) 2002;27(4):387-92.

6. Glassman SD, Bridwell K, Dimar JR, Horton W, Berven S, Schwab F. The impact of positive sagittal balance in adult spinal deformity. Spine (Phila Pa 1976) 2005;30(18):2024-9.
7. Lafage V, Schwab F, Patel A, Hawkinson N, Farcy JP. Pelvic tilt and truncal inclination: two key radiographic parameters in the setting of adults with spinal deformity. Spine (Phila $\mathrm{Pa}$ 1976) 2009;34(17):E599-606. CrossRef

8. Schwab F, Patel A, Ungar B, Farcy JP, Lafage V. Adult spinal deformity-postoperative standing imbalance: how much can you tolerate? An overview of key parameters in assessing alignment and planning corrective surgery. Spine (Phila Pa 1976) 2010;35(25):2224-31. CrossRef

9. Cutler HS, Guzman JZ, Maaieh MA, Connolly J, Skovrlj B, Cho SK. Patient Reported Outcomes in Adult Spinal Deformity Surgery: A Bibliometric Analysis. Spine Deformity 2015;3(4):312-7. CrossRef

10. Booth KC, Bridwell KH, Lenke LG, Baldus CR, Blanke KM. Complications and predictive factors for the successful treatment of flatback deformity (fixed sagittal imbalance). Spine (Phila Pa 1976) 1999;24(16):1712-20.

11. Bhalla A, Fayssoux R, Radcliff KE. Adult Spinal Deformity: Radiographic Parameters. Seminars in Spine Surgery 2015. CrossRef

12. Ryan DJ, Protopsaltis TS, Ames CP, Hostin R, Klineberg E, Mundis GM, Obeid I, Kebaish K, Smith JS, BoachieAdjei O, Burton DC, Hart RA, Gupta M, Schwab FJ, Lafage V; International Spine Study Group. T1 pelvic angle (TPA) effectively evaluates sagittal deformity and assesses radiographical surgical outcomes longitudinally. Spine (Phila Pa 1976) 2014;39(15):1203-10. CrossRef

13. Ames CP, Smith JS, Scheer JK, Bess S, Bederman SS, Deviren V, Lafage V, Schwab F, Shaffrey Cl. Impact of spinopelvic alignment on decision making in deformity surgery in adults: A review. J Neurosurg Spine 2012;16(6):547-64. CrossRef

14. Blondel B, Schwab F, Ungar B, Smith J, Bridwell K, Glassman S, Shaffrey C, Farcy JP, Lafage V. Impact of magnitude and percentage of global sagittal plane correction on healthrelated quality of life at 2-years follow-up. Neurosurgery 2012;71(2):341-8. CrossRef

15. Jackson RP, McManus AC. Radiographic analysis of sagittal plane alignment and balance in standing volunteers and patients with low back pain matched for age, sex, and size. A prospective controlled clinical study. Spine (Phila Pa 1976) 1994;19(14):1611-8.

16. Lafage V, Smith JS, Bess S, Schwab FJ, Ames CP, Klineberg $\mathrm{E}$, Arlet V, Hostin R, Burton DC, Shaffrey CI; International Spine Study Group. Sagittal spino-pelvic alignment failures following three column thoracic osteotomy for adult spinal deformity. Eur Spine J 2012;21(4):698-704. CrossRef

17. Schwab F, Farcy JP, Bridwell K, Berven S, Glassman S, Harrast J, Horton W. A clinical impact classification of scoliosis in the adult. Spine (Phila Pa 1976) 2006;31(18):2109-14.

18. Schwab F, Lafage V, Patel A, Farcy JP. Sagittal plane considerations and the pelvis in the adult patient. Spine (Phila Pa 1976) 2009;34(17):1828-33. CrossRef

19. Smith JS, Shaffrey CI, Fu KM, Scheer JK, Bess S, Lafage V, Schwab F, Ames CP. Clinical and radiographic evaluation of the adult spinal deformity patient. Neurosurg Clin N Am 2013;24(2):143-56. CrossRef

20. Kebaish KM. Spinal Sagittal Plane Deformities: Etiology, Evaluation, and Management. Seminars in Spine Surgery 2009;21(1):41-8.

21. Akbarnia BA, Crandall DG, Burkus K, Matthews T. Use of long rods and a short arthrodesis for burst fractures of the thoracolumbar spine. A long-term follow-up study. J Bone Joint Surg Am 1994;76(11):1629-35. 
22. Bess $S$, Boachie-Adjei O, Burton D, Cunningham M, Shaffrey C, Shelokov A, Hostin R, Schwab F, Wood K, Akbarnia B; International Spine Study Group. Pain and disability determine treatment modality for older patients with adult scoliosis, while deformity guides treatment for younger patients. Spine (Phila Pa 1976) 2009;34(20):2186-90. CrossRef

23. Smith JS, Shaffrey $\mathrm{Cl}$, Berven $\mathrm{S}$, Glassman S, Hamill C, Horton W, Ondra S, Schwab F, Shainline M, Fu KM, Bridwell K; Spinal Deformity Study Group. Improvement of back pain with operative and nonoperative treatment in adults with scoliosis. Neurosurgery 2009;65(1), 86-93. CrossRef

24. Smith JS, Shaffrey Cl, Berven S, Glassman S, Hamill C, Horton W, Ondra S, Schwab F, Shainline M, Fu KM, Bridwell K; Spinal Deformity Study Group. Operative versus nonoperative treatment of leg pain in adults with scoliosis: a retrospective review of a prospective multicenter database with two-year follow-up. Spine (Phila Pa 1976) 2009;34(16):1693-8. CrossRef

25. Smith JS, Shaffrey $\mathrm{Cl}$, Glassman SD, Berven SH, Schwab FJ, Hamill CL, Horton WC, Ondra SL, Sansur CA, Bridwell KH; Spinal Deformity Study Group. Risk-benefit assessment of surgery for adult scoliosis: an analysis based on patient age. Spine (Phila Pa 1976) 2011;36(10):817-24. CrossRef

26. Smith JS, Fu KM, Urban P, Shaffrey Cl. Neurological symptoms and deficits in adults with scoliosis who present to a surgical clinic: incidence and association with the choice of operative versus nonoperative management. J Neurosurg Spine 2008;9(4):326-31. CrossRef

27. Diebo BG, Ferrero E, Lafage R, Challier V, Liabaud B, Liu S, Vital JM, Errico TJ, Schwab FJ, Lafage V. Recruitment of compensatory mechanisms in sagittal spinal malalignment is age and regional deformity dependent. A full-standing axis analysis of key radiographical parameters. Spine (Phila $\mathrm{Pa}$ 1976) 2015;40(9):642-9. CrossRef

28. Farcy JP, Schwab FJ. Management of flatback and related kyphotic decompensation syndromes. Spine (Phila Pa 1976) 1997;22(20):2452-7.

29. Wiggins GC, Ondra SL, Shaffrey Cl. Management of iatrogenic flat-back syndrome. Neurosurg Focus 2003;15(3):E8.

30. Lu DC, Chou D. Flatback syndrome. Neurosurg Clin N Am 2007;18(2):289-94.

31. Barrey C, Roussouly P, Perrin G, Le Huec JC. Sagittal balance disorders in severe degenerative spine. Can we identify the compensatory mechanisms? Eur Spine J 2011;20 Suppl 5:626-33. CrossRef

32. Obeid I, Hauger O, Aunoble S, Bourghli A, Pellet N, Vital JM. Global analysis of sagittal spinal alignment in major deformities: correlation between lack of lumbar lordosis and flexion of the knee. Eur Spine J 2011;20 Suppl 5:681-5. CrossRef

33. Boulay C, Tardieu C, Hecquet J, Benaim C, Mouilleseaux B, Marty C, Prat-Pradal D, Legaye J, Duval-Beaupère G, Pélissier J. Sagittal alignment of spine and pelvis regulated by pelvic incidence: standard values and prediction of lordosis. Eur Spine J 2006;15(4):415-22.

34. Lafage V, Ames C, Schwab F, Klineberg E, Akbarnia B, Smith J, Boachie-Adjei O, Burton D, Hart R, Hostin R, Shaffrey C, Wood K, Bess S; International Spine Study Group. Changes in thoracic kyphosis negatively impact sagittal alignment after lumbar pedicle subtraction osteotomy: a comprehensive radiographic analysis. Spine (Phila Pa 1976) 2012;37(3):E180-7. CrossRef

35. Lafage V, Bharucha NJ, Schwab F, Hart RA, Burton D, Boachie-Adjei O, Smith JS, Hostin R, Shaffrey C, Gupta M, Akbarnia BA, Bess S. Multicenter validation of a formula predicting postoperative spinopelvic alignment. J Neurosurg Spine 2012;16(1):15-21. CrossRef
36. Schwab FJ, Patel A, Shaffrey CI, Smith JS, Farcy JP, BoachieAdjei O, Hostin RA, Hart RA, Akbarnia BA, Burton DC, Bess $\mathrm{S}$, Lafage V. Sagittal realignment failures following pedicle subtraction osteotomy surgery: are we doing enough?: Clinical article. J Neurosurg Spine 2012;16(6):539-46. CrossRef

37. Smith JS, Bess S, Shaffrey CI, Burton DC, Hart RA, Hostin R, Klineberg E; International Spine Study Group. Dynamic changes of the pelvis and spine are key to predicting postoperative sagittal alignment after pedicle subtraction osteotomy: a critical analysis of preoperative planning techniques. Spine (Phila Pa 1976) 2012;37(10):845-53. CrossRef

38. Smith JS, Shaffrey Cl, Lafage V, Blondel B, Schwab F, Hostin R, Hart R, O'Shaughnessy B, Bess S, Hu SS, Deviren V, Ames CP; International Spine Study Group. Spontaneous improvement of cervical alignment after correction of global sagittal balance following pedicle subtraction osteotomy. J Neurosurg Spine 2012;17(4):300-7. CrossRef

39. Schwab FJ, Blondel B, Bess S, Hostin R, Shaffrey $\mathrm{Cl}$, Smith JS, Boachie-Adjei O, Burton DC, Akbarnia BA, Mundis GM, Ames CP, Kebaish K, Hart RA, Farcy JP, Lafage V; International Spine Study Group (ISSG). Radiographical spinopelvic parameters and disability in the setting of adult spinal deformity: a prospective multicenter analysis. Spine (Phila Pa 1976) 2013;38(13):E803-12. CrossRef

40. Vaccaro AR, Silber JS. Post-traumatic spinal deformity. Spine (Phila Pa 1976) 2001;26(24 Suppl):S111-8.

41. Malcolm BW, Bradford DS, Winter RB, Chou SN. Posttraumatic kyphosis. A review of forty-eight surgically treated patients. J Bone Joint Surg Am 1981;63(6):891-9.

42. Schwab F, Lafage V, Farcy JP, Bridwell K, Glassman S, Ondra $S$, Lowe T, Shainline M. Surgical rates and operative outcome analysis in thoracolumbar and lumbar major adult scoliosis: Application of the new adult deformity classification. Spine (Phila Pa 1976) 2007;32(24):2723-30.

43. Roussouly P, Nnadi C. Sagittal plane deformity: an overview of interpretation and management. Eur Spine J 2010;19(11):1824-36. CrossRef

44. SRS Terminology Committee and Working Group on Spinal Classification Revised Glossary Terms 2000. Available at: http://www.srs.org/professionals/glossary/SRS_revised_ glossary_of_terms.htm

45. Stokes IA. Three-dimensional terminology of spinal deformity. A report presented to the Scoliosis Research Society by the Scoliosis Research Society Working Group on 3-D terminology of spinal deformity. Spine (Phila Pa 1976)1994;19(2):236-248.

46. Deinlein D, Bhandarkar A, Vernon P, McGwin G, Wall K, Reece B, Mckay J, Theiss S. Correlation of pelvic and spinal parameters in adult deformity patients with neutral sagittal balance. Spine Deformity 2013;1(6):458-63. CrossRef

47. Vialle R, Levassor N, Rillardon L, Templier A, Skalli W, Guigui $P$. Radiographic analysis of the sagittal alignment and balance of the spine in asymptomatic subjects. J Bone Joint Surg Am 2005;87(2):260-7.

48. Kim YJ, Bridwell KH, Lenke LG, Rhim S, Cheh G. An analysis of sagittal spinal alignment following long adult lumbar instrumentation and fusion to L5 or S: can we predict ideal lumbar lordosis? Spine (Phila Pa 1976) 2006;31(20)2343-52.

49. Weinstein SL, Ponseti IV. Curve progression in idiopathic scoliosis. J Bone Joint Surg Am 1983;65(4):447-55.

50. Grubb SA, Lipscomb HJ, Coonrad RW. Degenerative adult onset scoliosis. Spine (Phila Pa 1976) 1988;13(3):241-5. 
51. Legaye J, Duval-Beaupère G, Hecquet J, Marty C. Pelvic incidence: A fundamental pelvic parameter for threedimensional regulation of spinal sagittal curves. Eur Spine J 1998;7(2):99-103.

52. Lafage V, Schwab F, Vira S, Patel A, Ungar B, Farcy JP. Spinopelvic parameters after surgery can be predicted: a preliminary formula and validation of standing alignment. Spine (Phila Pa 1976) 2011;36(13):1037-45. CrossRef

53. Rose PS, Bridwell KH, Lenke LG, Cronen GA, Mulconrey DS, Buchowski JM, Kim YJ. Role of pelvic incidence, thoracic kyphosis, and patient factors on sagittal plane correction following pedicle subtraction osteotomy. Spine (Phila Pa 1976) 2009;34(8):785-91. CrossRef

54. Kobayashi T, Atsuta Y, Matsuno T, Takeda N. A longitudinal study of congruent sagittal spinal alignment in an adult cohort. Spine (Phila Pa 1976) 2004;29(6):671-6.
55. Roussouly P, Pinheiro-Franco JL. Sagittal parameters of the spine: biomechanical approach. Eur Spine J 2011;20 Suppl 5:578-85. CrossRef

56. Schwab F, Ungar B, Blondel B, Buchowski J, Coe J, Deinlein D, DeWald C, Mehdian H, Shaffrey C, Tribus C, Lafage V. Scoliosis Research Society - Schwab adult spinal deformity classification: a validation study. Spine (Phila Pa 1976) 2012;37(12):1077-82. CrossRef

57. Van Royen BJ, Toussaint HM, Kingma I, Bot SD, Caspers M, Harlaar J, Wuisman PI. Accuracy of the sagittal vertical axis in a standing lateral radiograph as a measurement of balance in spinal deformities. Eur Spine J 1998;7(5):408-12. 